\title{
Simulating the effects of climate change across the geographical distribution of two medicinal plants in the genus Nardostachys
}

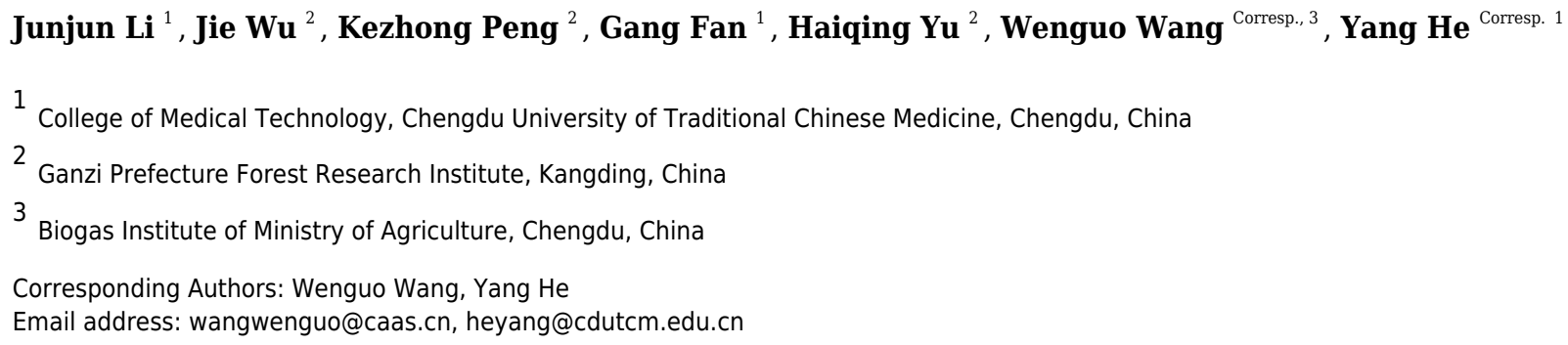

Background. The medicinal plants of Radix et Rhizoma Nardostachyos include Nardostachys jatamansi and $\mathrm{N}$. chinensis. Traditionally, the two plants have been used to treat many diseases. Because of their special aroma, they are also commonly used in the food and cosmetics industry. Recently, N. jatamansi and $N$. chinensis have been overexploited due to their economic importance, resulting in a sharp decline in their wild resources. Predicting potential distribution s of the genus Nardostachys under different climate scenarios and understanding its preferred habitat are of great significance for their conservation, artificial cultivation, and assessment of their value.

Methods. Maxent was used to predict the potential geographical distributions of the genus Nardostachys under current and future climatic conditions based on two representative concentration pathways (RCP2.6 and RCP8.5) for the 2050s and 2070s. These data were used to study the effects of climate variables.

Results. The results show that the potential distribution of the two species will increase, thus more suitable habitats will be present in China. The suitable habitat for $N$. chinensis presents a relatively stable growth compared to $N$. jatamansi . In addition, precipitation plays a crucial role in modeling the effects of climate change on the genus Nardostachys. This study provides theoretical guidance for the cultivation of $N$. chinensis. 


\section{Simulating the effects of climate change across the geographical}

\section{2 distribution of two medicinal plants in the genus Nardostachys}

3 Junjun $\mathrm{Li}^{1}$, Jie $\mathrm{Wu}^{2}$, Kezhong Peng ${ }^{2}$, Gang Fan ${ }^{1}$, Haiqing $\mathrm{Yu}^{2}$, Wenguo Wang ${ }^{3}$, Yang $\mathrm{He}^{1}$

4

$5{ }^{1}$ College of Medical Technology, Chengdu University of Traditional Chinese Medicine, Chengdu, 611137,

6 China

$7 \quad{ }^{2}$ Ganzi Prefecture Forest Research Institute, Kangding, 626001, China

$8 \quad{ }^{3}$ Biogas Institute of Ministry of Agriculture, Chengdu, 610041, China

9

Corresponding Authors.

11 Wenguo Wang

12 Biogas Institute of Ministry of Agriculture, Chengdu, 610041, China

Email address:wangwenguo@caas.cn

Yang He

College of Medical Technology, Chengdu University of Traditional Chinese Medicine, Chengdu, 611137,

China

Email address:heyang@cdutcm.edu.cn 
Abstract

Background. The medicinal plants of Radix et Rhizoma Nardostachyos include Nardostachys jatamansi and $N$. chinensis. Traditionally, the two plants were used to treat many diseases. And because of their special aroma, they're also commonly used as a spice in the food and cosmetics industry. Enormous economic value has caused the two plants to be overexploited in recent years, resulting in a sharp dropping in their wild resources. Predicting potential distributions of the genus Nardostachys under different climate scenarios and understanding their suitable ecological factors are of great significance for their conservation, artificial cultivation, and value assessment.

Methods. MaxEnt was used to predict the potential geographical distributions of the genus

Nardostachys under current and future climatic conditions based on two representative concentration pathways(RPC2.6 and RPC8.5) for the year 2050s and 2070s, and study the effects of climate variables. Results. The results show that potential distribution of the two plants both will have an increase in the number of suitable areas in China. However, the suitable habitat area 
Introduction

57

According to the Chinese Pharmacopoeia, the medicinal plants of Radix et Rhizoma Nardostachyos include Nardostachys jatamansi and N. chinensis (Pharmacopeia Committee of P R. China, 2015). These species are perennial, rhizomatous, in the family Valerianaceae (Airi et al., 2000). N. jatamansi is about 5 to $50 \mathrm{~cm}$ in height, with a thick and long woody stem. The dark gray main root is thick and long, densely covered with the leaf sheath fibers, with strong fragrance (Bhat \& Malik, 2017; Zhang et al., 2016). The main difference between N. jatamansi and $N$. chinensis is that the obliquely stretched rhizome of the $N$. jatamansi, which with more dense leaf-based fibers to cover the stem, and the corolla tube is wider and shorter (Flora of China Editorial Committee, 2006). Also, N. jatamansi is mainly found growing between altitudes of 3300-5000 m, and it originated to the elevated ranges of the Himalayas in Nepal but also found in the high lands of Sikkim, Bhutan and Punjab (Malik et al., 2018). In China, these species were primarily distributed in the eastern part of the Tibetan Plateau and its margins (Flora of China Editorial Committee, 2006). Although there are some differences in the morphology and distribution of these two species, they contain similar active ingredients and medical efficacy (An Editorial Committee of the Administration Bureau of Traditional Chinese Medicine, 2000). These rhizomes have been used in Chinese traditional medicine. Their medicinal properties include anti-epileptic, anticonvulsant, anti-depressant, anti-inflammatory, sedation, antiarrhythmic, antiparkinson, antibacterial, hypolipidemia, hepatoprotection, and nerve development (Ahmad et al., 2013). Recent research showed that the rhizome contains chemical components such as sesquiterpenes, flavonoids, polysaccharides, and lignans (Chatterjee et al., 2005). Because of the high content and special aroma of sesquiterpenes, these species have also been used for flavoring (Le et al., 2017).

Due to their wide application in medicine, food, cosmetics, and other industries, the market demand for the two species was increasing. However, due to the underdevelopment of the cultivation technology of Nardostachys, the industry mainly depended on wild resources. To 
82

83

meet the demands of the market, excessive wild collection has led to a sharp decrease in wild Nardostachys populations and serious habitat destruction. Measures need to be taken to protect the species and develop artificial planting technology for them.

The development of effective cultivation and protection of Nardostachys species is required to better meet the market demands and sustainably use the species. For long-term and effective development of cultivation of the Nardostachys species, it is essential to understand its suitable climate and geographic distribution in future.

Environmental factors have significant influences on the distribution of species. Global climate change is occurring at an unprecedented rate. And the global temperatures are expected to rise significantly in this century, even the greenhouse gas concentrations remain constant at the year 2000 levels (Rivaes et al., 2013). RCPs (Representative Concentration Pathways) were used in climate modeling and research to describe the four possible future climates in the fifth assessment report of the Intergovernmental Panel on Climate Change (IPCC, 2013). The four $\mathrm{RCPs}$ (RCP2.6, RCP4.5, RCP6, and RCP8.5) are named in the possible range of Radiative Forcing values in the year 2100 relative to pre-industrial values $(+2.6,+4.5,+6.0$, and +8.5 $\mathrm{W} / \mathrm{m}^{2}$, respectively) (Ma \& Sun, 2018).

Species distribution models could simulate the potential ecological niche of a species from various hypotheses about how environmental factors control the distribution of species and communities based on known occurrence points (Zhang et al., 2016). Therefore, the species distribution models could provide the basis for planting land selection and growing climatic conditions during the cultivation of the two plants. The main Species distribution models for species distribution predictions include Bioclim, Climex, Domain, Garp, and Maxent maximum entropy modeling. Among these models, the Maxent model has a strong advantage in predicting species distribution and gained popularity, which is a presence-only modeling technique using a machine learning approach (Phillips et al., 2006). The Maxent model has successfully completed the prediction of the potential geographical distributions of multiple species for the past few years, including Fritillaria cirrhosa, Lilium nepalense, Phellodendron amurense Rupr, and 
Atractylodes lancea (Rana et al., 2017; Wan et al., 2014; Zhu et al., 2017).

Radix et Rhizoma Nardostachyos is an endangered and valuable Chinese herbal medicine that needs to be protected and developed. Moreover, its two medical plants with similar medical effects, and more importantly, the two species are on the verge of extinction. For better utilization and development of Radix et Rhizoma Nardostachyos, climate change was used as a screening factor to select one species that is more suitable for artificial cultivation. The subject of this paper is to discover the effects of climate change on the two species by the Maxent model, and provide a basis for their artificial cultivation.

\section{Materials and Methods}

The complete analysis workflow was summarized in Figure 1.

\section{Basic geographic data}

A 1:400,000 vector map of China's administrative divisions was downloaded from the national basic geographic information system (NFGIS) as the base map for the analysis.

\section{Study area}

$N$. jatamansi and $N$. chinensis were mainly distributed in subalpine to alpine areas, where the elevation is more than 3,000 meters. The Qinghai-Tibetan Plateau is the main distribution area, ranging from $25^{\circ}$ to $40^{\circ} \mathrm{N}, 74^{\circ}$ to $104^{\circ} \mathrm{E}$. The Qinghai-Tibetan Plateau is the world's highest plateau, with an altitude of between 3,000 and 5,000 meters and an average elevation of over 3,500 meters. The climate of the Qinghai-Tibetan Plateau is monsoonal. The annual average temperature in most parts of the region is below $8^{\circ} \mathrm{C}$, and the annual precipitation is $400-900$ $\mathrm{mm} /$ year.

\section{Data collection}

Occurrence records of $N$. jatamansi and $N$. chinensis were mainly obtained through online databases and consulting literature. The online database includes the Chinese Virtual Herbarium (http://www.cvh.ac.cn/), Specimen Resources Sharing Platform for Education (http://mnh.scu.edu.cn/), and Global Biodiversity Information Facility (https://www.gbif.org/). 
The literature used was open-source and available worldwide. In the absence of specific geographical coordinate records, Google Earth 7.0 was utilized to find the approximate latitude and longitude according to the described geographical location. After duplicate and invalid records were removed, the sampling points of $N$. jatamansi and $N$. chinensis were 183 and 60 , respectively. We obtained sampling points from the specimen database and literature, and all the specimens collected in the specimen database are wild. In accordance with the requirements of the Maxent software, the distribution records of $N$. jatamansi and $N$. chinensis were organized into .csv format files including the species name and distribution point longitude and latitude, with the east and north latitudes positive and the west and south latitudes negative.

\section{Environmental variables}

Climate variables are crucial in simulating the distribution of species. This article mainly analyzed the impact of climate change on the distribution of $N$. jatamansi and $N$. chinensis. Refer to other literature, nineteen bioclimatic variables with 2.5-minute resolution of the current conditions and future conditions (2050s and 2070s) were downloaded from the WorldClimGlobal Climate Data (http://worldclim.org/) (Suwannatrai et al., 2017). The 2.5-minute resolution could meet the simulation requirements based on the published article (Bai et al., 2018; Qu et al., 2018). These variables are derived from monthly temperature (maximum and minimum) and rainfall data, which express seasonality, annual trends and extreme conditions (Mendoza-González et al., 2013). The 19 bioclimatic variables with strong biological significance explained the adaptation of species with extreme environmental factors. Here, two greenhouse gas concentration scenarios, RCP 2.6 (the minimum greenhouse gas emission scenario) and RCP 8.5 (the maximum greenhouse gas emission scenario) were selected under the CCSM4 (The Community Climate System Model version 4.0) model in this work. Referring to the research of Ma and Sun, RCP2.6 and RCP8.5 are the most common emissions scenarios $(M a$ $\&$ Sun, 2018). The CCSM4 climate model, which was developed by the National Center for Atmospheric Research of the United States, has been thoroughly evaluated in China. It has recently been verified that the CCSM4 model can better simulate the climate characteristics of 
East Asia (Tian \& Jiang, 2013).

\section{Distribution modeling}

The Maxent model was a widely used and effective model for species distribution modeling because it produced believable results. It is based on the freely available Maxent software V3.3.3k (http://www.cs.princeton.edu/_schapire/maxent/). Maxent was used to predict the current and future potential distributions of $N$. jatamansi and $N$. chinensis based on the occurrence records and climate data. The logical output (results are expressed in terms of probability) was selected to assess the likelihood of the presence of a species in each grid cell. Twenty-five percent of the occurrence records were chosen as the test set, and the remaining parameters were the default settings (Yi et al., 2016). Jackknifing in the environment parameter settings was checked to measure the percentage contribution of each environmental variable and to evaluate the importance of environmental factors in affecting the geographical distribution of species.

The area under the receiver operating curve (ROC), called AUC, was used to evaluate the accuracy of the prediction results (Zhang et al., 2016). AUC values range from 0 to 1 , and the larger the AUC value, the farther away from the random distribution. High AUC values indicate the better prediction of the model. AUC values generally range from 0.5 to 0.7 when accuracy is low; moderate accuracy is generally $0.7 \sim 0.9$; a high degree of accuracy is typically greater than 0.9 (Wakie et al., 2014).

\section{Results}

Occurrences of $N$. jatamansi and $N$. chinensis

Figure 2 showed the original occurrences of $N$. jatamansi and $N$. chinensis were mainly distributed in Sichuan Province, parts of Yunnan, Gansu, and Qinghai Provinces, and the Tibetan Autonomous Region. The main areas in which $N$. jatamansi was distributed were the Tibetan Autonomous Region, Sichuan Province, Yunnan Province, and a small part of Qinghai and Gansu Provinces. In addition, $N$. jatamansi was also distributed in other countries including India 
and Nepal. Hence, the distribution of $N$. jatamansi is more extensive than that of $N$. chinensis.

\section{Predicting the distribution under current conditions}

Figure 3 (A, B) showed the predicted area of distribution for $N$. jatamansi and $N$. chinensis by the Maxent model under the current climate conditions. The simulation output results from the Maxent software are between 0 and 1. According to a previously published article by Wang et al (2014), the results were divided into four levels: 0-0.05, 0.05-0.25, 0.25-0.5, and 0.5-1. Elith et al (2011) considered that the average probability of species being present in suitable areas was 0.5. For the two species in this study, the area with probabilities above 0.5 was the main natural distribution area. Thus, the probabilities above 0.5 was defined as suitable habitats, and probabilities less than 0.5 were unsuitable based on the study of Wang et al (2018).

As showed in Fig. 3 (A, B), suitable areas under current conditions of $N$. jatamansi were mainly distributed in the Qinghai-Tibetan Plateau in China, including western parts of Sichuan Province, northern Yunnan Province, the eastern part of the Tibetan Autonomous Region, and a small part of southern Qinghai and Gansu Provinces. In addition, it has a small suitable area in India, Bhutan, and Nepal. Among these distributions, the suitable areas of Sichuan, Tibet, and Yunnan are extensive and concentrated in the high mountain plateau region, which was roughly in line with the records of the distribution of $N$. jatamansi.

Suitable areas of $N$. chinensis were mainly distributed at the junction of the Tibetan Autonomous Region and Sichuan and Qinghai Provinces in China. Sichuan Province has the most suitable habitats. This was consistent with the collection records from Sichuan, indicating that $N$. chinensis was primarily distributed in the province, and no suitable habitats were indicated in other countries. According to the prediction, the area in which N. jatamansi is distributed was significantly larger than the distribution of $N$. chinensis under current conditions.

\section{The effects of climate change on the geographical distribution of $N$. jatamansi and $N$.}

\section{chinenis}

Figure 3 (B-E and G-J) showed the potential geographical distributions of $N$. jatamansi and $N$. chinenis predicted by the Maxent model under the CCSM4 of the 2050s and 2070s. There 
217

218

219

220

221

222

223

224

225

226

227

228

229

230

231

232

233

234

\section{5}

236

237

238

239

240

241

242

243

was an overall upward trend in the area of suitable habitats for $N$. jatamansi and $N$. chinensis (Fig. 4).

By 2050, suitable areas (RCP2.6 and RCP8.5) of $N$. jatamansi increased. Relative to the current situation, both ranges increased in RCP2.6 and RCP8.5 with a greater growth rate under RCP8.5. The scope of suitable areas in Qinghai and Tibet increased obviously and exhibited a trend of northward expansion. Suitable areas of $N$. chinensis under RCP2.6 and RCP8.5 emissions scenarios also increased compared to the current situation. The scope of suitable areas in western Sichuan Province and Tibet increased obviously and also exhibited a trend of northward expansion.

By 2070, the area of suitable habitats for $N$. jatamansi under the RCP2.6 emission scenario will continue to grow. However, the range of suitable areas under the RCP8.5 emission scenario was significantly reduced and was significantly lower than the current level. The results showed that the climate-suitable area decreased in the 2070s under the RCP8.5 climate scenario compared to the current period.

Suitable areas of $N$. chinensis under RCP2.6 also continued to increase, relative to the $2050 \mathrm{~s}$ and the present. Suitable areas of $N$. chinensis under RCP8.5 still increased compared to the present. However, suitable areas of $N$. chinensis under RCP8.5 decreased from the 2050s.

\section{Contribution of environmental variables}

Nineteen bioclimatic variables from the BIOCLIM climate dataset were used as the background environmental data, such as temperature and rainfall. These variables are comprehensive conclusions and quantitative descriptions of the climatic environment in the regions containing the targeted species. The potential distributions of $N$. jatamansi and $N$. chinensis were simulated by the Maxent model, which automatically predicted the contribution percentage of each variable to the forecasted results. Table 1 listed selected bioclimatic variables and their percent contribution in the Maxent model for $N$. jatamansi and N. chinensis in their current distribution range. Among them, precipitation of the driest period (Bio14) was the largest 
244

245

246

247

248

249

250

251

252

253

254

255

256

257

258

259

260

261

262

263

264

265

266

267

268

269

270

contributing factor when modeling the distributions of $N$. jatamansi and $N$. chinensis.

The jackknife test also showed that precipitation of the coldest quarter (Bio19), precipitation of the driest quarter (Bio17), and precipitation of the driest period (Bio14) were the main variables in the simulation of $N$. chinensis (Fig. 5). However, isothermality (Bio3), precipitation seasonality (Bio15), and precipitation of the driest period (Bio14) were the main factors affecting the modeled distribution of $N$. jatamansi (Fig. 5).

Figure 6 showed the response curves for single climate variables in the Maxent forecast of $N$. jatamansi and $N$. chinensis. Response curves indicated the correlation between the environmental variables used for prediction and the probability of the presence of $N$. jatamansi and $N$. chinensis. In Fig. 6, Bio14 response curves peak in the distribution predictions of $N$. jatamansi and $N$. chinensis. The distribution probability of $N$. jatamansi and $N$. chinensis increased with the increase of variable value. After exceeding this peak, the distribution probability decreased with the increase of the value for environmental factors, indicating that $N$. jatamansi and $N$. chinensis have some adaptability to these variables. When the probability is greater than 0.5 , the corresponding ecological factor value is more suitable for the growth of the plant.

The prediction showed that the best ranges for these indicators were precipitation of the driest month, 1-5 $\mathrm{mm}$ for $N$. chinensis and 0-10 $\mathrm{mm}$ for $N$. jatamansi. The optimum range of precipitation of the driest month is very narrow, indicating that $N$. jatamansi and $N$. chinensis were sensitive to precipitation.

\section{Discussion}

With global warming, upon changes in temperature, precipitation, and $\mathrm{CO}_{2}$ concentration, and the changes in certain climatic resources changed the dynamics and balance of different species, thereby affecting their productivity. When the distributions of climate resources adapting to $N$. jatamansi and $N$. cdinensis change, the geographical distributions also undergo corresponding changes. The temperature increases strongly under RCP8.5 and may exceed the suitable temperature for plant growth $(L v \& Z h o u, 2018)$. Thus, the climate-suitable area 
271

272

273

274

275

276

277

278

279

280

281

282

283

284

285

decreased in the 2070s under the RCP8.5 climate scenario compared to the current period.

This indicated that more areas will be suitable for the distribution of $N$. jatamansi, which would have greater potential for expansion in China in the future under a low-emission scenario, contrary to high-emission scenarios. In addition, suitable areas in Qinghai and Tibet decreased obviously and exhibited a trend of northward expansion. Nevertheless, suitable sites in the high altitude area of Tibet markedly increased. And previous studies have shown that with global warming, some species will migrate to high latitude or high elevation (Zhang et al., 2018). The variation of the suitable area of $N$. jatamansi was consistent with this result.

Ma and Sun (2018) had predicted the distribution of Stipa purpurea across the Tibetan Plateau via the Maxent model. The habitat suitability of S. purpurea in RCP2.6 and RCP8.5 revealed that the habitat suitability for the species increased from the 1990s to 2050s, then decreased from the 2050s to 2070s. Their results indicated the trend of the suitable habitat area was consistent with our prediction. However, they also considered the impact of topographic variables in the study, which was our shortcoming.

According to the above results, the suitable habitat $N$. jatamansi varies greatly under different climate scenarios and was more affected by climate change. However, the potential distributions of $N$. chinensis showed a growing trend in different climate scenarios compared to its current situation and was less affected by climate change. Therefore, in order to avoid the impact of climate change on the artificial cultivation of the genus Nardostachys, and achieve stable development, we could choose $N$. chinensis as the main cultivated species.

Studying the interaction between species and the environment is an essential aspect of species cultivation. The relationship between the probability of species presence and dominant environmental variables was analyzed in this paper. And the percent contribution of bioclimatic variables, the jackknife test and the response curves were created by the MaxEnt software.

According to the results of above forecase, we can conclude that precipitation of the driest period is the most important environmental factor affecting the growth of $N$. chinensis and $N$. jatamansi. And the research has shown that while comparing the distribution of the two 
contrasting hill slopes (east and west), the density of $N$. jatamansi has increased significantly with altitude was revealed on a west-facing slope. And the north and west-facing slopes in the alpine zone of this region are broadly considered as the shady areas with low light and high moisture (Airi et al., 2000). And the advantage of high water and nutrient supply for rhizome and root production has also been reported elsewhere for related valerian species (Bernat, 1997). These results indicated that the precipitation plays a dominant role in simulating the effects of climate change on $N$. jatamansi and $N$. chinensis compared to temperature and other environmental variables.

The analysis for the response curves showed that the probability of species presence changed as a result of the dominant environmental variables. And the results indicated that $N$. jatamansi and $N$. chinensis were sensitive to precipitation.Thus, this showed that research on water management should be strengthened for future cultivation practices.

\section{Conclusion}

The results of this Maxent simulation of climate change impacts on the distribution of two Nardostachys species and prediction of their potential distributions under current and future climate conditions are reliable. Considering the effects of climate change, $N$. chinensis is more suitable for cultivation. In addition, precipitation of the driest period is an important factor in the impact of climate change on $N$. jatamansi and $N$. chinensis. It is of great significance to study the impact of climate change on the genus Nardostachys to predict their potential distribution in the future for the protection, sustainable use, and value assessment of these biological resources. It is essential to conduct future studies on the effect of watering of $N$. chinensis for developing effective techniques to cultivate $N$. chinensis. And the study will provide references for the cultivation planning and resource utilization of $N$. jatamansi and $N$. chinensis.

\section{References}

Ahmad A, Sattar MZA, Rathore HA, Tabinda F, Safia AK, Sheryar A, Mohamed L, Fiaz-u-Din A, Eseyin O. 2013. Pharmacological importance of Nardostachys jatamansi DC: A 
potential therapeutic agent in different pathological ailments. Journal of chemical and pharmaceutical research, 5: 431-438.

Airi RS, Rawal, Dhar U, Purohit AN. 2000. Assessment of availability and habitat preference of Jatamansi - a critically endangered medicinal plant of west Himalaya. Current Science, 79:1467-1471.

An Editorial Committee of the Administration Bureau of Traditional Chinese Medicine. 2000. Chinese Materia Medica (Zhonghua Bencao), Shanghai Science and Technology Press: Shanghai, China.

Bai Y, Wei X, Li X. 2018. Distributional dynamics of a vulnerable species in response to past and future climate change: a window for conservation prospects. PeerJ, 6:e4287.

Bernath, J. 1997. in Valerian - the Genus Valeriana (ed. Houghton, P. J.), Harwood Academic Publishers, UK, pp. 77-100.

Bhat MDA, Malik R. 2017. Pharmacological Profile and Uses of Sumbul-ut-teeb (Nardostachys jatamansi) in Unani System of Medicine. International Journal of Advanced Complementary and Traditional Medicine, 3:51-58.

Chatterjee A, Basak B, Datta U, Banerji J, Neuman A, Prange T. 2005. Studies on the Chemical Constituents of Nardostachys jatamansi DC (Valerianaceae). Indian Journal of Chemistry, 36: $430-433$.

Edenhofer O, Seyboth K. 2013. Intergovernmental Panel on Climate Change (IPCC). Encyclopedia of Energy Natural Resource and Environmental Economics, 26: 48-56.

Elith J, Phillips SJ, Hastie T, Dudı 'k M, Chee YE, Yates CJ. 2011. A statistical explanation of MaxEnt for ecologists. Diversity and Distributions, 17: 43-57.

Flora of China Editorial Committee. 2006. Flora of China. Vol, 22, Science Press and Missouri Botanical Garden Press, Beijing, 7.

Houghton JT, Ding Y, Griggs DJ. 2001. Climate Change 2001: The Scientific Basis.Contribution of Working Group I to the Third Assessment Report of the Intergovernmental Panel on Climate Change (IPCC). Cambridge:Cambridge University Press, 2001:944. 
352

353

354

355

356

357

358

359

360

361

362

363

364

365

366

367

368

369

370

371

372

373

374

375

376

377

378

379

IPCC. IPCC Climate Change 2013: The Physical Science Basis. Working Group I Contribution to the Fifth Assessment Report of the Intergovernmental Panel on Climate ChangeSummary for Policymakers; IPCC: Geneva,Switzerland, 2013.

Jiang H, Liu T, Li L, Zhao Y, Pei L, Zhao J. 2016. Predicting the Potential Distribution of Polygala tenuifolia Willd. under Climate Change in China. Plos One, 11(9): e0163718.

Le, VNH, Khong TQ, Na MK, Kim KT, Kang JS. 2017. An optimized hplc-uv method for quantitatively determining sesquiterpenes in nardostachyos radix et rhizoma. Journal of Pharmaceutical and Biomedical Analysis, 145: 406.

Lv X, Zhou G. 2018. Climatic Suitability of the Geographic Distribution of Stipa breviflora in Chinese Temperate Grassland under Climate Change. Sustainability, 10:3767.

Ma B, Sun J. 2018. Predicting the distribution of Stipa purpurea across the Tibetan Plateau via the MaxEnt model. BMC Ecology, 18:10.

Malik R, Firdose KF, Bhat MDA. 2018. Efficacy of Nardostachys jatamansi DC. in the management of premenstrual syndrome: A randomized controlled study. Journal of Herbal Medicine, 14:17-21.

Masui T, Matsumoto K, Hijioka Y, Kinoshita T, Nozawa T, Ishiwatari S, Kato E, Shukla PR, Yamagata Y, Kainuma M. 2011. An emission pathway for stabilization at $6 \mathrm{Wm}-2$, radiative forcing. Climatic Change, 109: 59-67.

Moss RH, Edmonds JA, Hibbard KA, Manning MR, Rose SK, van Vuuren DP, Carter TR, Emori S, Kainuma M, Kram T, Meehl GA, Mitchell JFB, Nakicenovic N, Riahi K, Smith SJ, Stouffer RJ, Thomson AM, Weyant JP, Wilbanks TJ. 2010. The next generation of scenarios for climate change research and assessment. Nature, 463: 747-756.

Pharmacopeia Committee of P.R.China. 2010. Pharmacopoeia of People's Republic of China. China Medical Science \& Technology Press. Beijing.

Phillips SJ, Anderson RP, Schapire RE. 2006.Maximum entropy modeling of species geographic distributions. Ecological Modelling, 190: 231-259.

Qu H, Wang CJ, Zhang ZX. 2018. Planning priority conservation areas under climate change for six plant species with extremely small populations in China. Nature Conservation, 25:89- 
106.

Rana SK, Rana HK, Ghimire SK, Shrestha KK, Ranjitkar S. 2017. Predicting the impact of climate change on the distribution of two threatened Himalayan medicinal plants of Liliaceae in Nepal. Journal of Mountain science, 14: 558-570.

Riahi K, Rao S, Krey V, Cho CH, Chirkov V, Fischer G, Kindermann G, Nakicenovic N, Rafaj P. 2011. RCP 8.5-A scenario of comparatively high greenhouse gas emissions. Climatic Change, 109: 33-57.

Rivaes R, Rodrí guez - González PM, Albuquerque A, Pinheiro AN, Egger G, Ferreira MT. 2013. Riparian vegetation responses to altered flow regimes driven by climate change in Mediterranean rivers. Ecohydrol, 6: 413-424.

Rivaes RP, Rodr1 'guez-Gonza'lez PM, Ferreira MT, Pinheiro AN, Politti E, Egger G, GarcíaArias A, Francés F. 2014. Modeling the Evolution of Riparian Woodlands Facing Climate Change in Three European Rivers with Contrasting Flow Regimes. Plos One, 9(10): e110200.

Suwannatrai A, Pratumchart K, Suwannatrai K, Thinkhamrop K, Chaiyos J, Kim CS, Suwanweerakamtorn R, Boonmars T, Wongsaroj T, Sripa B. 2017. Modeling impacts of climate change on the potential distribution of the carcinogenic liver fluke, Opisthorchis viverrini, in Thailand. Parasitoogyl Research, 116:243-250.

Thomson AM, Calvin KV, Smith SJ, Kyle GP, Volke A, Patel P, Delgado-Arias S, BondLamberty B, Wise MA, Clarke LE, Edmonds JA. 2011. RCP4.5: a pathway for stabilization of radiative forcing by 2100. Climatic Change, 109: 77-94.

van Vuuren, DP, Stehfest E, den Elzen MGJ, Kram T, van Vliet J, Deetman S, Isaac M, Goldewijk KK, Hof A, Beltran AM, Oostenrijk R, van Ruijven B. 2011 RCP2.6: exploring the possibility to keep global mean temperature increase below $2^{\circ} \mathrm{C}$. Climatic Change, 109(1): 95-116.

Wakie TT, Evangelista PH, Jarnevich CS, Laituri M. 2014. Mapping current and potential distribution of non-native Prosopis juliflora in the Afar region of Ethiopia. Plos One, 9: 11. 
407

408

409

410

411

412

413

414

415

416

417

418

419

420

421

422

423

424

425

426

427

428

429

430

431

Wan JZ, Wang CJ, Yu JH, Nie SM, Han SJ, Zu YG, Chen CM, Yuan SS, Wang QG. 2014. Model-based conservation planning of the genetic diversity of Phellodendron amurense Rupr due to climate change. Ecology and Evolution, 4(14): 2884-2900.

Wang R, Li Q, He S, Liu Y, Wang M, Jiang G. 2018. Modeling and mapping the current and future distribution of Pseudomonas syringae pvactinidiae under climate change in China. Plos One, 13(2): e0192153.

Wang WG, Tang XY, Zhu QL, Pan K, Hu QC, He MX, Li JT. 2014. Predicting the Impacts of Climate Change on the Potential Distribution of Major Native Non-Food Bioenergy Plants in China. Plos One, 9: 11.

Yi YJ, Cheng X, Yang ZF, Zhang SH. 2016. Maxent modeling for predicting the potential distribution of endangered medicinal plant (H. riparia, Lour) in Yunnan, China. Ecological Engineering, 92: 260-269.

Zhang L, Cao B, Bai CK, Li GS, Mao MC. 2016. Predicting suitable cultivation regions of medicinal plants with Maxent modeling and fuzzy logics: a case study of Scutellaria baicalensis, in China. Environmental Earth Sciences, 75: 361.

Zhang K, Yao L, Meng J, Tao J. 2018. Maxent modeling for predicting the potential geographical distribution of two peony species under climate change. The Science of The Total Environment, 634:1326-1334.

Zhao Q, Li R, Gao YY, Yao Q, Guo XQ, Wang WG. 2018. Modeling impacts of climate change on the geographic distribution of medicinal plant Fritillaria cirrhosa D. Don. Plant Biosystems, 152(3), 349-355.

Zhu SD, Peng HS, Guo LP, Xu TR, Zhang Y, Chen ML, Hao QX, Kang LP, Huang LQ. 2017. Regionalization of Chinese Material Medical Quality Based on Maximum Entropy Model: A case study of Atractylodes lancea. Scientific Reports, 7: 42417. 


\section{Table $\mathbf{1}$ (on next page)}

Table 1 . Bioclimatic variables used for model construction and their percentage contribution in predicting the current distribution of $N$. jatamansi and $N$. chinensis using Max E nt. 
1 Table1. Bioclimatic variables used for model construction and their percentage contribution in predicting the 2 current distribution of $N$. jatamansi and N. chinensisusing MaxEnt.

3

\begin{tabular}{|c|c|c|c|}
\hline \multirow{2}{*}{ Abbreviation } & \multirow{2}{*}{ Discription } & \multicolumn{2}{|c|}{ Percent contribution } \\
\hline & & N.jatamansi & N.chinensis \\
\hline Biol & Annual Mean Temperature $\left({ }^{\circ} \mathrm{C}\right)$ & 0.8 & 1.5 \\
\hline Bio2 & $\begin{array}{l}\text { Mean Diurnal Range (Mean of monthly } \\
(\max \text { temp-min temp) })\left({ }^{\circ} \mathrm{C}\right)\end{array}$ & 0.1 & 0 \\
\hline Bio3 & Isothermally (Bio2/Bio7) $(\times 100)$ & 15.4 & 7.7 \\
\hline Bio4 & $\begin{array}{l}\text { Temperature Seasonality (standard } \\
\text { deviation } \times 100)(\mathrm{C} \text { of } \mathrm{V})\end{array}$ & 0.1 & 0 \\
\hline Bio5 & Max Temperature of Warmest Month $\left({ }^{\circ} \mathrm{C}\right)$ & 5.2 & 8.1 \\
\hline Bio6 & Min Temperature of Coldest Month $\left({ }^{\circ} \mathrm{C}\right)$ & 0.5 & 3.4 \\
\hline Bio7 & Temperature Annual Range $(\mathrm{Bio} 5-\mathrm{Bio} 6)\left({ }^{\circ} \mathrm{C}\right)$ & 0.3 & 0.3 \\
\hline Bio8 & Mean Temperature of Wettest Quarter $\left({ }^{\circ} \mathrm{C}\right)$ & 9.6 & 9.6 \\
\hline Bio9 & Mean Temperature of Driest Quarter $\left({ }^{\circ} \mathrm{C}\right)$ & 0.3 & 0 \\
\hline Bio10 & Mean Temperature of Warmest Quarter $\left({ }^{\circ} \mathrm{C}\right)$ & 5.3 & 2.7 \\
\hline Bio11 & Mean Temperature of Coldest Quarter $\left({ }^{\circ} \mathrm{C}\right)$ & 0.2 & 0 \\
\hline Bio12 & Annual Precipitation(mm) & 0.2 & 0.1 \\
\hline Bio13 & Precipitation of Wettest Month(mm) & 13 & 15.2 \\
\hline Bio14 & Precipitation of Driest Month(mm) & 36 & 36 \\
\hline Bio15 & Precipitation Seasonality (C of V) & 0.6 & 0.1 \\
\hline Bio16 & Precipitation of Wettest Quarter(mm) & 0.1 & 2.5 \\
\hline Bio17 & Precipitation of Driest Quarter(mm) & 8.6 & 0.2 \\
\hline Bio18 & Precipitation of Warmest Quarter(mm) & 0.5 & 0.1 \\
\hline Bio19 & Precipitation of Coldest Quarter(mm) & 3.4 & 12.6 \\
\hline
\end{tabular}




\section{Figure 1}

Figure 1 . The processing method in the flowchart

The study mainly included three processes of data preparation, Maxent simulation and comprehensive evaluation. 


\section{Dada preparation}

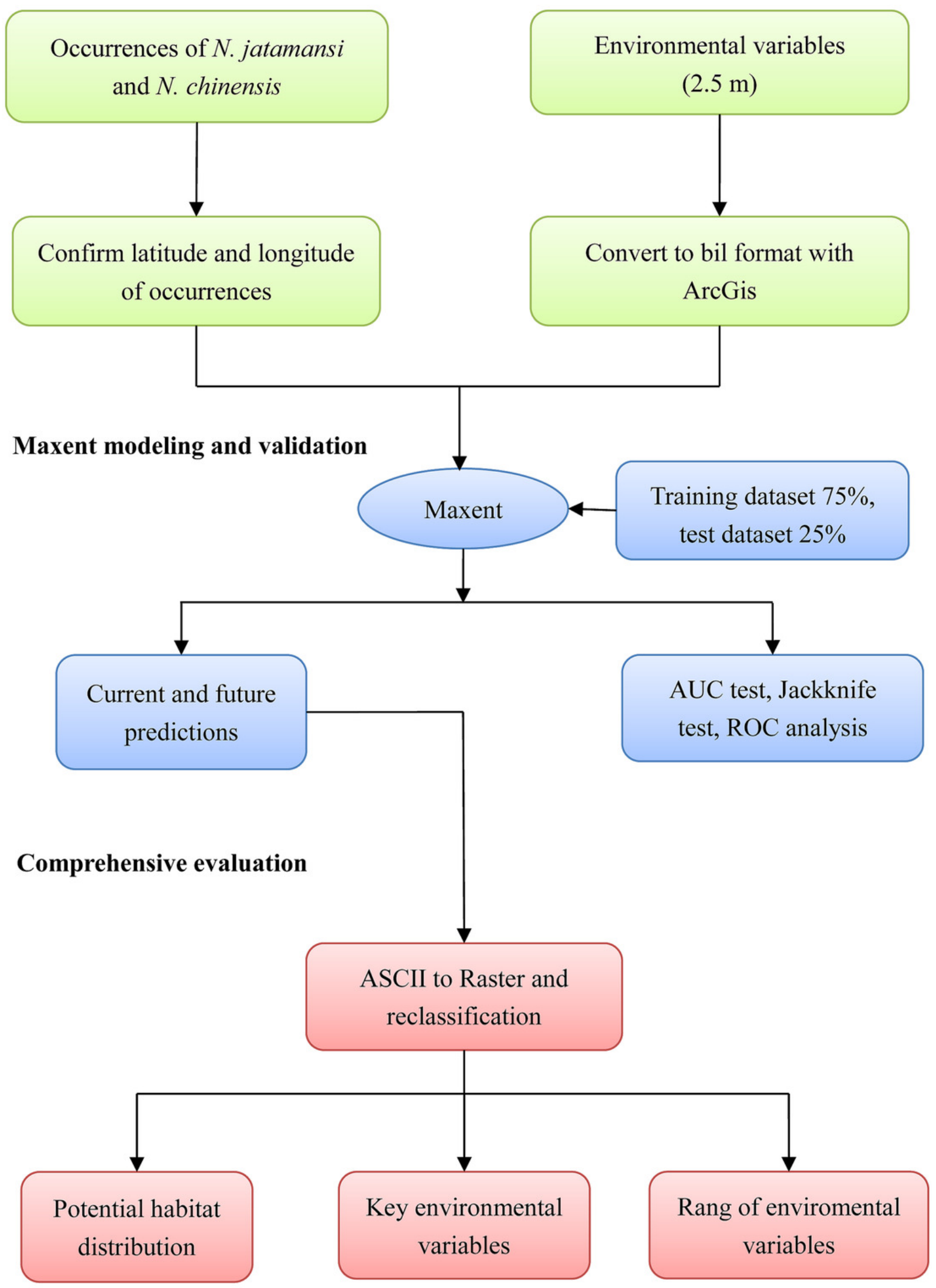


Figure 2

Figure 2. The original occurrence records

Red dots represented georeferenced locations of 60 occurrences of $N$. chinensis (A), and black dots represented georeferenced locations of 183 occurrences of $N$. chinensis in Qinghai-Tibetan Plateau (B) .

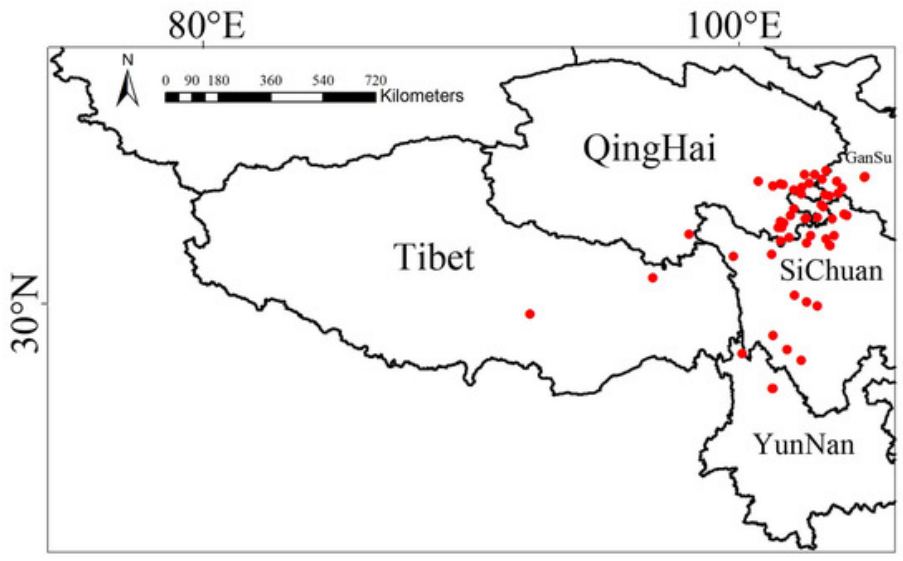

- N. chinensis

- N. jatamansi

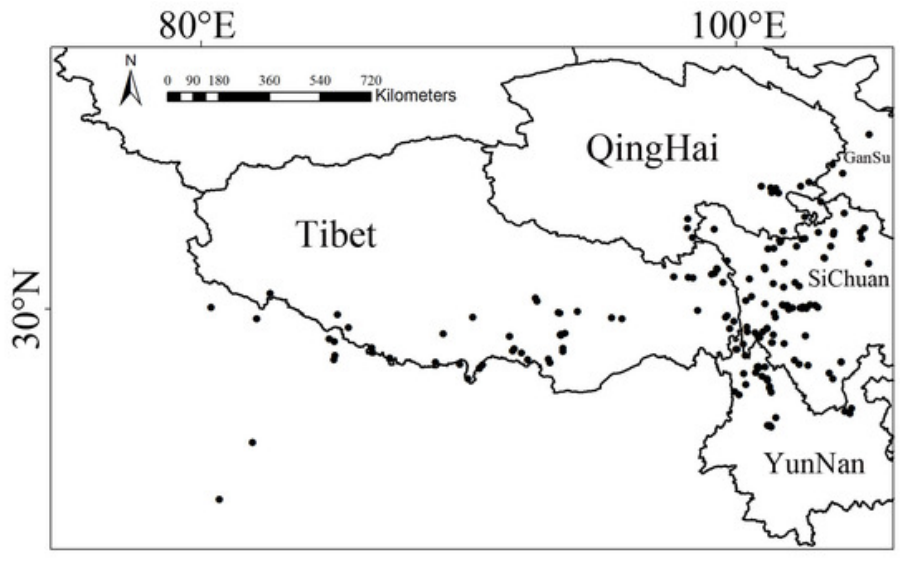

(B) 


\section{Figure 3}

Figure 3. Present ( $\mathrm{A}$ and $\mathrm{F})$, and future (B-E and $\mathrm{I}-\mathrm{L}$ ) potential spatial distribution of $N$. jatamansi and $N$. chinensis

Future predictions (2050s and 2070s) were based on two representative concentration pathways under CCSM4 climate model.

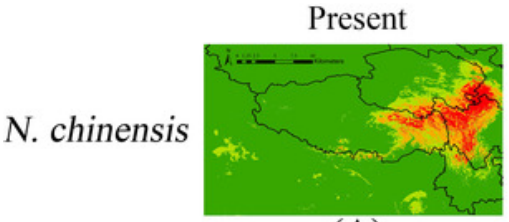

(A)

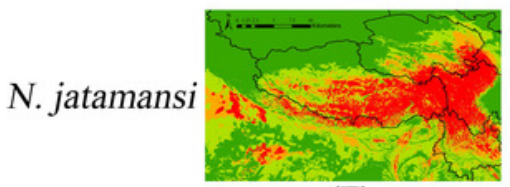

(F)

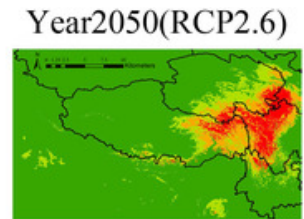

(B)

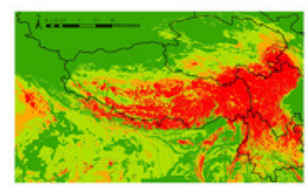

(G)

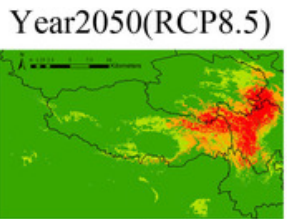

(C)

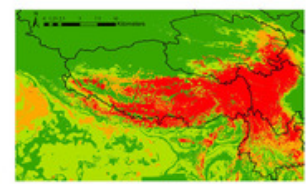

(H)

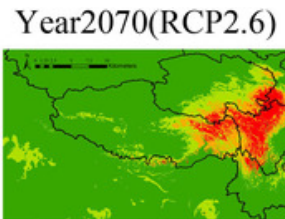

(D)

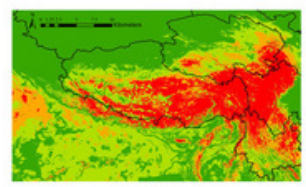

(I)

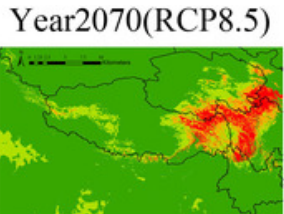

(E)

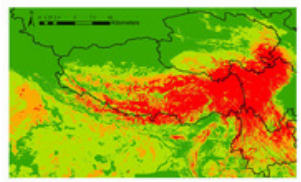

(J)

Climatic suitability

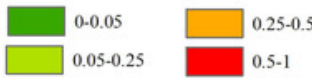




\section{Figure 4}

Figure 4. The area of suitable habitats of $N$. jatamansi and $N$. chinensis for present and future conditions predicted by Maxent based on CCSM4 climate model

There was an overall upward trend in the area of suitable habitats for $N$. jatamansi and $N$. chinensis.

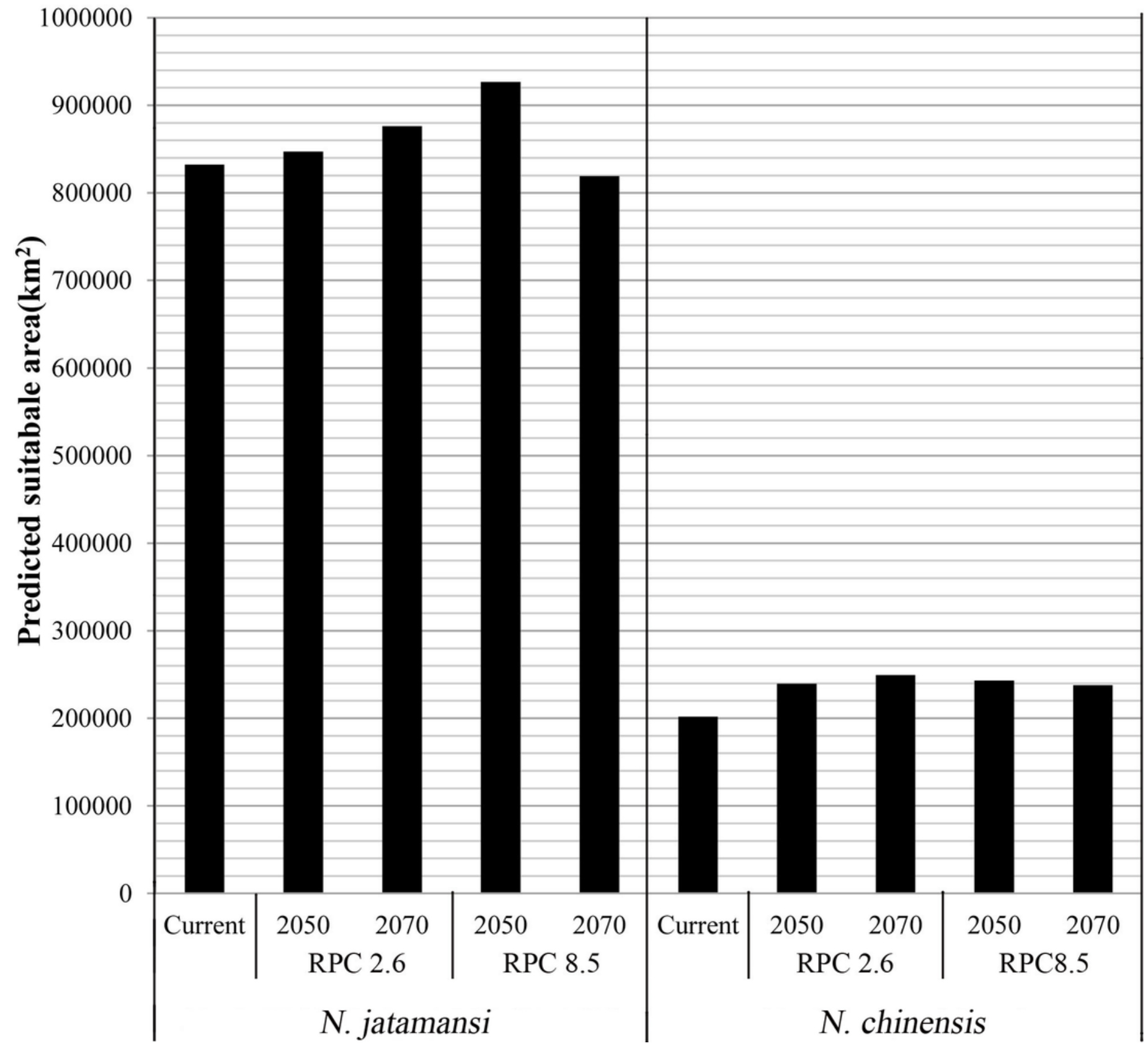




\section{Figure 5}

Figure 5. The Jackknife test for evaluating the relative importance of environmental variables for $N$. jatamansi and $N$. chinensis

The blue, aqua and red bars represent the results of the model created with each individual, all remaining variables and all the variables respectively .

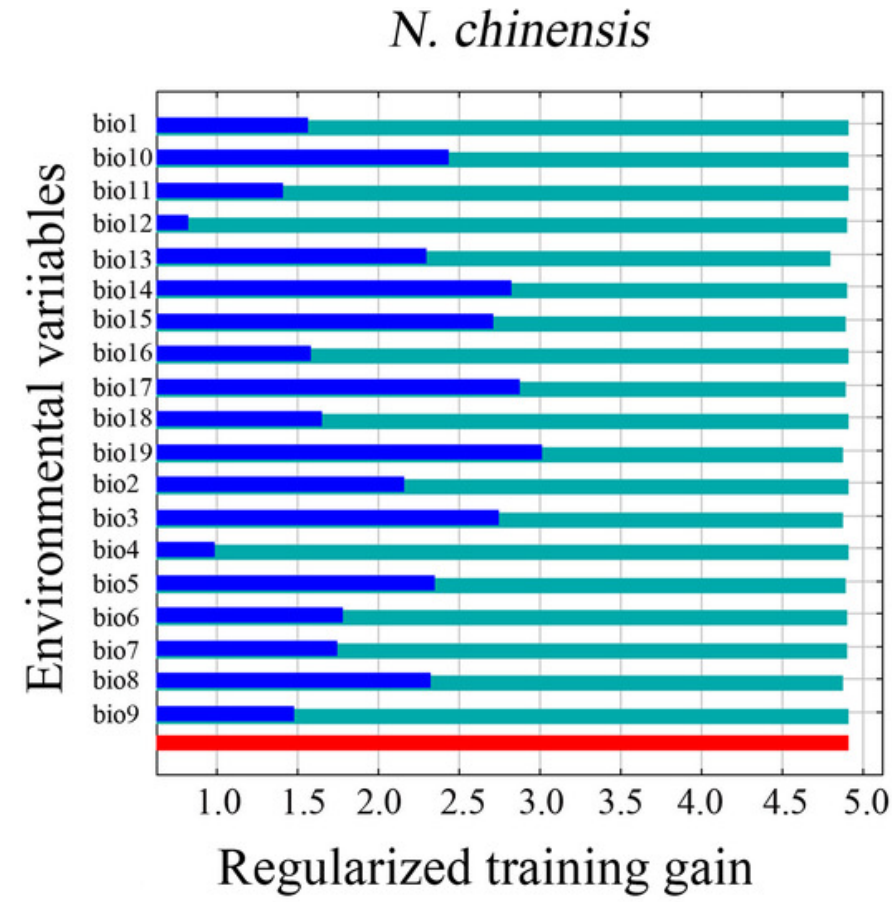

Without variable

\section{(A)}

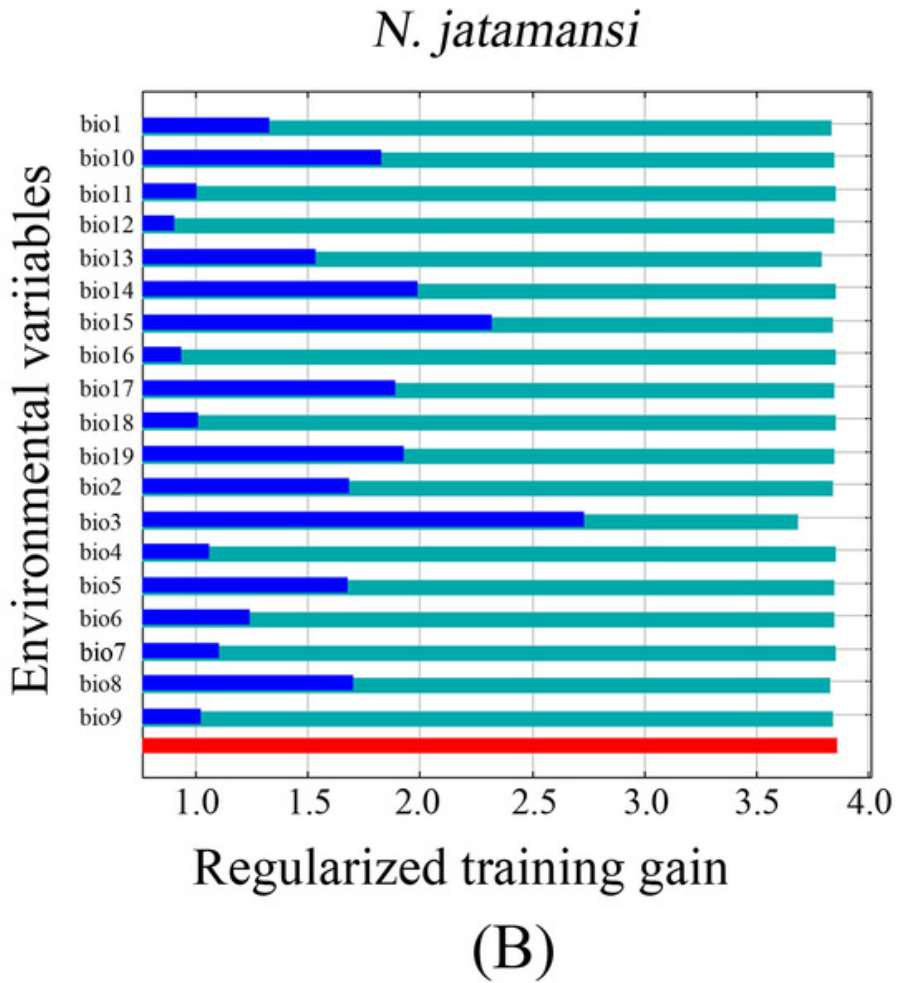

With only variable

With all variables 
Figure 6

Figure 6. The response curves of precipitation of driest month under the current period

Response curves indicated the correlation between the environmental variables used for prediction and the probability of the presence of $N$. jatamansi and N. chinensis.

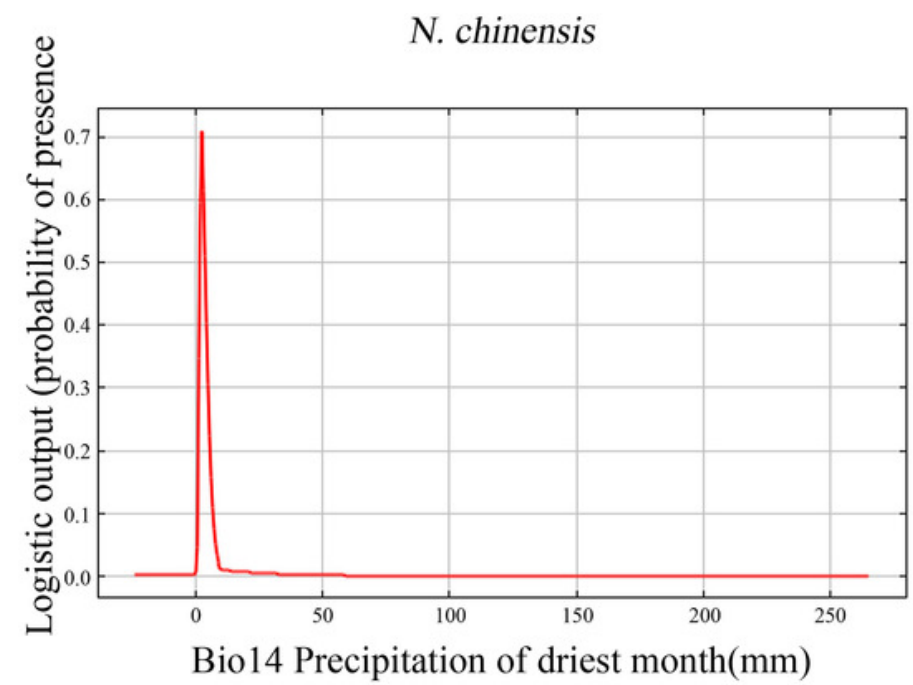

(A)

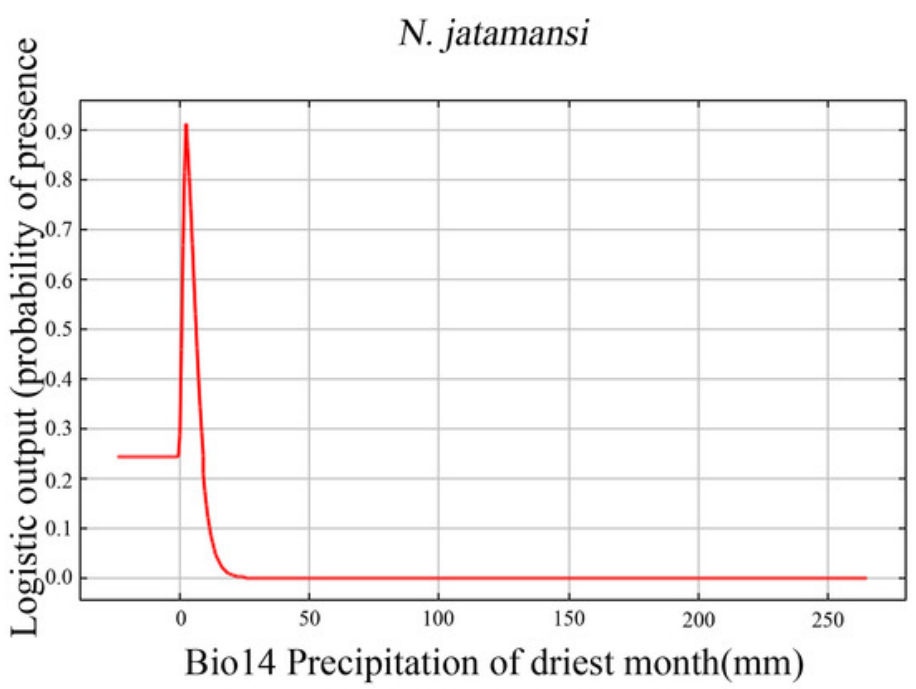

(B) 